\title{
ETHICS IN COMMUNICATION: INTRODUCTORY NOTE
}

\author{
Joaquim Fidalgo \& Rogério Christofoletti
}

The new media landscape has brought to public debate a set of new concerns and challenges, regarding the problems of ethics in communication. It is rather clear that ethical issues associated to communication have always provoked strong public controversies, but they didn't necessarily become very present in the research agendas of academic and scientific institutions. Often associated to simple moralistic perspectives, or just reduced to a set of common-sense assertions about good or bad social behavior, the ethical dimension of public communication has not always been adequately valued as a rational, conscious and critical process of choices based on principles committed with truth, trust and the human dignity.

In spite of this, more and more voices have come to stress the importance of an ethical commitment regarding all the actors involved in public communication; at the same time, they point precisely to the lack of ethics as one of the most worrisome signs of a communicative activity that often disrespects the basic requirements of a healthy social life. This means that the subject of ethics remains highly topical and relevant in the field of the communication studies, calling for more and more research that may help us to better understand and improve the communicative processes in complex societies like those we live in nowadays. Moreover, the technological developments of the digital age, and particularly the dissemination of Internet and its multiple opportunities for on-line communication, brought new problems and new challenges to the media environment, either in what concerns the professional context of some specific sectors (journalism, advertising, public relations, multimedia production), or in what regards the citizens in general, who presently have (or may have) in the public sphere a voice they hadn't in the past. More and more, ethics isn't anything that only matters to professionals or to mainstream organizations of communication and the media; instead, it also affects and involves the audience, which is becoming more and more an active participant and a co-author of the communicative process in the public sphere. Furthermore, ethics is now (and will be more in the future) a decisive element to distinguish between what is acceptable and what is not, between what is right and what is wrong, between what actually respects the human dignity of all people and what doesn't.

Taking this background into consideration, the journal "Comunicação e Sociedade" ["Communication and Society"] decided to organize a special issue devoted to the problems of Ethics in Communication, involving its multiple dimensions. The call for papers was really successful and about 30 articles, coming from most various countries, were submitted. In the sequence of the blind peer-reviewing process that evaluated the papers (with the involvement of reviewers both from Portugal and Brazil), the eight that ranked higher were selected for publication. You may read them in the Part 2 of this issue.

Part 1 consists of four essays specifically written for this special issue by some of the most prominent scholars in the area of communication ethics worldwide. Clifford 
Christians (USA), Jane B. Singer (USA, but presently working in the UK), Carlos MaciáBarber (Spain) and Carlos Camponez (Portugal) were the researchers invited to participate. They kindly accepted, which really honors us, and they wrote four stimulating texts that make an inestimable contribution to the reflection we propose with this dossier.

Clifford Christians makes an exhaustive review of the issues associated to media ethics at an international level, recalling important steps in the timeline of this internationalization process. After analyzing the most relevant international theories on media ethics, he returns to the theme, dear to him, of the universal values that underlying those theories (truth, human dignity, non-violence), regarding them as a common platform for an worldwide consensus that may contribute to a stronger ethical commitment in the domain of public communication.

As for Jane B. Singer, she discusses the turmoil that the digital environment brought to the issues of communication, and most particularly to journalism, whose professionals have been showing some problems dealing with the new realities surrounding us (blogs, social media, user-generated content...). And ethics, as she says, has been sometimes used as a crutch, rather than as a legitimate claim for professional self-affirmation. Insisting on the centrality of the ethical values, this scholar appeals to the journalists' openness to innovation and flexibility, urging them to meet right now the increasing challenges of the near future.

But ethics doesn't only concern journalists and communication professionals. As is emphasized by Carlos Maciá-Barber, it also concerns the media companies and corporations, as well as their managers and directors, particularly in a situation where the traditional 'business model' seems to be failing. More investment on the companies' social responsibility (which means more openness to accountability mechanisms and to quality certification), as well as on stimuli to more public participation, are, according to the Spanish researcher, two increasing demands that will meet positively the ethical challenges of the present days.

Carlos Camponez draws our attention to the importance of an ethics of care as an answer to the problems of credibility presently faced by journalism. Based on the respect for the individuality of the 'Other', this ethical orientation, according to the author, may help to counterbalance the logics of commercialization, of audience shares and of entertainment that dominate contemporary media, giving them a more human dimension that will make them more trustworthy and close to the real people.

Starting Part 2 of this special issue, Luis Mauro Sá Martino e Ângela Cristina Salgueiro Marques develop some work on the conceptions of ethics that are present in the main Communication Theories. From an historical-critical perspective, the authors deal with the issues of power and of the communicative ability of the political subject, articulating them with the ethical demands.

In an approach closer to media practice, Paulo Martins discusses the complex ethical problem of respect for privacy, matched with the citizens' rights to information and to free speech. He argues that respect for anyone's private sphere must be taken into account not only in the moment of the public diffusion of news, but also during the process 
of news gathering, particularly when information sources or actors implied in the events are to be found in a situation of fragility.

Turning more clearly to the field of new, online media, Mohammad Ofiul Hasnat reflects on the structure of presentation of news in the social media, raising questions about their credibility and about the ways they are, or aren't, able to gain the trust from their audience. The analysis of the situation in Finland, complemented by a set of interviews to Finnish professional journalists, brings interesting data to this debate.

The article by Elsa Costa e Silva also looks at social media, and more specifically at blogs. Starting from some ethical controversies that have been raised in the Portuguese blogosphere, particularly in the area of blogs dedicated to politics, the author discusses the opportunity of regulation of these new communicative platforms - and even the possibility of creation of an ethics code especially addressed to bloggers.

Many bloggers, even when they deal with timely news and information, are not professional journalists - and don't intend to be. The article written by Rogério Christofoletti focus precisely on journalism made by non-journalists, and particularly on some ethical concerns they go together with this new scenario. Based on a couple of recent concrete situations, the author brings to debate the issues of proximity or distance between the values and standards followed by amateurs, and those subscribed by professional journalists. Furthermore, he tries to open the way to new opportunities for cooperation between both parts in the process of news making.

J. Paulo Serra discusses the borders that separate journalism from propaganda, arguing that the possibilities of access and of use of Internet by the citizens in general help to counterattack eventual propagandistic trends of the conventional media. Admitting that these trends have caused a major crisis in journalism, he pledges for a permanent and systematic restatement of ethics as a pre-condition to overcome that crisis.

The questions of propaganda are also present in the article by Marius-Adrian Hazaparu: he researched on hybrid genres, where journalistic information and advertising are deliberately mixed (advertorials), in order to serve economic interests. Analyzing a very eloquent case study from Romania, the author insists on the need to evaluate the ethical behavior in advertising not only according to its final results, but also according to the context of its preparation and production.

Advertising is again the main theme of the last article of this issue, written by Paulo Barroso. After putting sensitive questions about the relationship between advertising and morality, he recalls that advertising has different ethical implications because of the strategies it uses, which may be tricky or fallacious. The paper concentrates on a critical analysis of ethics in advertising and in communication, evoking some relevant theoretical contributions on the theme.

The diversity of approaches and the variety of proposals that compose this special issue of our journal, some of them more focused on theoretical reflections and some more associated with empirical research, will offer a very stimulating reading opportunity 
for everyone who cares about the issues of ethics in communication. These issues are, probably more than ever, in the public agenda both of professionals, managers, academics and 'lay' citizens, because all of them somehow believe that this is a sensitive area to try to face the time of crisis we live in. And ethics plays certainly a major role in the attempts to improve the communicative processes and to involve all its partners (professionals, industries, institutions, and public) in a joint effort towards more transparency, more trust and more active participation in the building of citizenship.

We would like to thank all the authors for their invaluable contribution to this special issue of "Comunicação e Sociedade".

The editors

Joaquim Fidalgo (CECS - Universidade do Minho - Portugal) Rogério Christofoletti (Universidade Federal de Santa Catarina - Brasil) 